\title{
ESTIMATIVA DO GRAU DE INFESTAÇÃO NUMA PASTAGEM DE Panicum maximum JACQ
}

\section{G. DE MARINIS*}

\section{RESUMO}

Um piquete de capim-colonião (Panicum maximum Jacq) submetido a pas toreio contínuo e a roçadas periódicas revelou, seis anos após o plantio, elevado grau de infestação por outras plantas, destacando-se entre elas a grama-batatais (Paspalum notatum Flügge) que apresentou $85 \%$ de frequência e $20,9 \%$ de biomassa epígea seca relativa. As dicotiledóneas, em conjunto, apresentaram frequência de $95 \%$ e biomassa relativa de $38,7 \%$ mas a sua contribuição específica foi muito reduzida. O capim-colonião, por sua vez, apesar da frequência de 95\%, apresentou apenas $32,2 \%$ de biomassa relativa (diminuição de 67,8\%). Estas profundas alterações da flora e da vegetação podem ser atribuidas, em grande parte, a dois fatores: a) ação seletiva da roçadeira; b) preferências alimentares e disseminação endozoócora da gramabatatais pelos bovinos.

UNITERMOS: Malerbologia, Pastagens, Panicum maximum Jacq., Paspalum notatum Flügge, Competição.

\section{SUMMARY}

ON THE DEGREE OF WEED INFESTATION IN A PASTURE OF Panicum maximum JACQ

A pasture of Guineagrass (Panicum maximum Jacq.) submitted to continuous grazing and periodic clearing revealed, after six years from its planting, a high degree of weed infestation. Bahiagrass (Paspalum notatum Flügge) exhibited a frequency of $85 \%$ and a relative dry epigeous biomass of $20,9 \%$. Dicotyledons as a whole exhibited a frequency of $95 \%$ and a relative biomass of $38,7 \%$. On the other hand, Guineagrass, although
* Professor-Titular, Departamento de Botânica, Instituto de Biociências de Rio Claro, Universidade Estadual Paulista .Julio de Mesquita Filho». 13.500 Rio Claro, SP.

Recebido para publicação em 06.06.78

with a frequency of $95 \%$, exhibited a relative biomas s of only $32,2 \%$ equivalent to a decrease of $67,8 \%$. This great floristic and vegetational change may be ascribed to mechanical selective action of the scythe and to grazing selection and zoochorous dissemination of Bahiagrass by cattle.

HEYWORDS: Weeds, Pastures, Panicum maximum Jacq., Paspalum notatum Flügge, Competition.

\section{INTRODUÇÃO}

A pastagem artificial de capimcolonião (Panicum maximum Jacq.) constitui o sustentáculo de uma importante atividade pecuária e chega a ser a tônica da paisagem na região norteocidental do Estado de São Paulo. Quando sujeita à deterioração, a pastagem passa a ser invadida por diversas plantas, cujo estudo é de grande interesse.

Do ponto de vista fitossociológico, a consocies antrópica Panicetum maximi transforma-se numa associes de composição variável, na qual o capimcolonião pode perder a dominância ou mesmo desaparecer. Do ponto de vista agronômico, algumas espécies invasoras possuem valor forrageiro (certas leguminosas e gramineas) mas a maioria são malerbas, de pouca ou ne- 
nhuma palatabilidade, ou de menor valor nutritivo ou, às vezes, tóxicas.

$O$ presente trabalho visa verificar algumas modificações da flora e da vegetação ocorridas numa pastagem de capim-colonião, após seis anos a partir da sua implantação. Ao exame visual esta pastagem se apresentava fortemente infestada por outras plantas, entre as quais se destacava a grama-batatais (Paspalum notatum Flügge).

Capim-colonião e grama-batatais pertencem a gêneros próximos dentro da tribo Paniceae (Potztal, 10) mas diferem consideravelmente no hábito e na origem geográfica. $P$. maximum é um capim cespitoso, erecto, que pode alcançar 2,5 m de altura, enquanto que $P$. notatum é uma grama rizomatosa as cendente, de 15 a $50 \mathrm{~cm}$ de altura (Hitchcock, 8). 0 primeiro é nativo da África tropical e amplamente naturalizado na América e Asia, enquanto que o segundo é essencialmente neotrópico, desde o México e Índias ocidentais até a Argentina (Hitchcock, 8; Potztal, 10).

As duas espécies são cultivadas como forrageiras (Araújo, 1), e a respeito do capim-colonião existem informações de Furlan (7) obtidas em ensaios com plantas envasadas e de Pedreira (9) obtidas em condições de campo; algumas características da forragem foram estudadas por Bose (4).

Ambas são malerbas muito abundantes no Brasil, de novicidade moderada no caso do capim-colonião e alta no caso da grama-batatais (Blanco, 3).

\section{MATERIAIS E MÉTODOS}

Foi estudado um piquete de cerca de 1 ha de área, situado na Estação Experimental de Zootecnia de São José do Rio Preto (SP). O clima desta cidade, segundo Arid et al. (2) é tropical quente-úmido com verão chuvoso e inverno seco (tipo AW de Koeppen). A fase climática seca, durante a qual as precipitações são inferiores à evapotranspira cão, vai de abril a setembro, enquanto que na fase úmida, de outubro a março, as precipitações cons eguem quase sempre saturar o solo e fornecer excedentes. Durante os seis anos de duração do piquete estudado, houve, de permeio, um biênio de estiagem acentuada, com pluviosidade insuficiente para sustentar a eva poração.

Segundo a Comissão de Solos (5), a Estação Experimental de Zootecnia de São José do Rio Preto está situada em solo podzolizado de Lins e Manilia, var. Lins.

No piquete estudado empregou-se periodicamente (três vezes por ano em média) uma roçadeira regulada a $30 \mathrm{~cm}$ de altura.

O levantamento em que se baseiam os resultados do presente trabalho foi feito através de 200 parcelas de $50 \times 50 \mathrm{~cm}\left(0,25 \mathrm{~m}^{2}\right)$ cada uma, localizados por sorteio. Em cada parcela foram coletadas todas as plantas vasculares existentes no dia 10 de abril de 1970, correspondente à fase inicial do outuno. O material coletado foi repartido em quatro grupos, correspondentes ao capim-colonião, à grama-batatais, às outras gramíneas (principalmente Cynodon dactylon Pers. e Cenchrus echinatus L.) e às dicotiledõneas. Todas as plantas foram cortadas rente à superfície do solo, levadas para uma estufa a $105-110^{\circ} \mathrm{C}$ e submetidas a secagem até peso constante. Obteve-se, assim, a biomassa epigea seca (Bes) cujos valores foram reduzidos a $\mathrm{kg} / \mathrm{ha}$. Foi também calculada a frequência $(F)$ em porcentagem do número total de parcelas estudadas.

\section{RESULTADOS E DISCUSSÃO}

Os resultados do presente trabalho (Quadro 1) evidenciaram em primeiro lugar, o avançado grau de deteriora-cão do piquete. Seu ocupante inicial, o capim-colonião, que após a formação do pasto constituia praticamente $100 \%$ 
QUADRO 1 - Biomassa epigea seca (Bes) e frequência (F).

\begin{tabular}{lcc}
\hline & Bes & F \\
\hline Panicue ou grupo de espécies & $32,2 \%$ & $95 \%$ \\
Paspalum notatum Jacq. & $20,9 \%$ & $85 \%$ \\
Outras gramineas & $8,2 \%$ & $55 \%$ \\
Dicotiledôneas & $38,7 \%$ & $95 \%$ \\
\hline
\end{tabular}

da biomassa, passou a representar apenas $1 / 3$ do total, sofrendo uma redução relativa de $67,8 \%$. Do ponto de vista da freqüência, o recuo do colonião foi muito pequeno, apenas 5\%, mostrando que este não abandonou de maneira significativa a área inicial mas decaiu quanto à cobertura, permitindo a infiltração de outras plantas.

Em segundo lugar, ficou patente a agressividade da grama-batatais que, além de se alastrar por quase toda a área $(\mathrm{F}=85 \%)$ chegou a representar $1 / 5$ da biomassa total. As demais gramineas (principalmente Cynodon dactylon Pers. e Cenchrus echinatus L.) apesar de sua natureza altamente agressiva, permaneceram inferiorizadas, representando apenas $8,9 \%$ da biomassa total.

Em terceiro lugar, as dicotiledôneas, tomadas em conjunto, apresentaram biomassa relativa considerável (mais de 1/3) e frequência quase total $(\mathrm{F}=95 \%)$. Por outro lado, nenhuma dicotiledônea apresentou índices específicos dignos de menção e foi por este motivo que todas elas foram consideradas em bloco. Cumpre notar que o número de espécies dicotiledôneas encontradas no piquete (ao redor de trinta) não é particularmente elevado. Na mesma Estação Experimental, em local próximo, numa área equivalente e submetida a condições muito semelhantes, De Marinis (6), aos 90 dias após o termino da limpeza completa do solo, através de repetidas arações e gradagens, encontrou 76 espécies. Este fato sugere a hipótese de o capim-colonião ter ofereci do considerável resistência ao estabelecimento das espécies infestantes, muito embora não se possa excluir a ocorrência de competição eliminatória entre as próprias dicotiledôneas. O fato é que nenhuma planta latifoliada conseguiu alcançar, durante os seis anos, qualquer grau expressivo de dominância especifica.

As causas prováveis desta considerável alteração florística e vegetacional ocorrida no piquete podem ser incluídas em dois itens:

a) Ação seletiva mecânica exercida pe la roçadeira, a favor das plantas baixas ou semi-rasteiras (principalmente grama-batatais) e contra as plantas erectas mais altas (inclusive o capim-colonião).

b) Ação seletiva biológica exercida pelos bovinos, através de preferências alimentares (seleção de dicotiledõneas, principalmente não leguminosas, em prejuizo das gramineas) e através da disseminação endozoócora (seleção da grama-batatais) de acordo com Araújo (1, pg. 196).

Os resultados do presente trabalho apontam alguns aspectos interessantes da deterioração das pastagens e da competição entre plantas cultivadas e espontâneas. $\mathrm{O}$ aspecto talvez mais notável é o destaque atribuído, no caso, a dois fatores de seletividade (o mecânico e o biológico) raramente considerados pelos malerbologistas, que se preocupam quase exclusivamente com a seletividade herbicídica. 


\section{AGRADECIME NTOS}

Ao Eng. ${ }^{\circ}$ Agr. ${ }^{\circ}$ Paulo Gastão da Cunha, Chefe da Estação Experimental de Zootecnia de São José do Rio Preto, por ter permitido e facilitado a execução do presente trabalho.

\section{LITERA TURA CITADA}

1. Araújo, A.A. de. Pastagens artificiais, São Paulo, Ediçóes Melhoramentos, 1956. 253p.

2. Arid, F.M.; Castro, P.R.M. e Barcha, S.F. Estudos hidrogeológicos no Municipio de São José do Rio Preto, SP. Bol. Soc. Bras. Geol. 19 (1): 43-69, 1970.

3. Blanco, H.G. Catálogo das espécies de mato infestantes de áreas cultivadas no Brasil: Gramineas perenes. O Biológico, 41 (5): 130$143,1975$.

4. Bose, M.L.V. Composição em fibra bruta, celulose e lignina, digestibilidade da celulose in vitro e em C.E.D. dos capins coloniảo, gordura, jaraguá, napier e pangola, em crescimento vegetativo. Piracicaba, ESALQ-USP. (Tese), 1971. 63p.

i. Comissão de Solos, Centro Nacional de Ensino e Pesquisas Agronómicas. Carta dos Solos do Estado de Sáo Paulo, 1960.

i. De Marinis, G. Nota sobre a determinação da área mínima de uma comunidade infestante inicial de pastagens. In: Sem. Reg. Ecologia, São Carlos, 1973. Resumos, p. 87.

'. Furlan, $\mathbf{R}$. da $\mathbf{S}$. Influència da frequência $\mathbf{e}$ intensidade de corte no capim coloniảo $(\mathrm{Pa}$ nicum maximum Jacq.) Piracicaba, ESALQ -USP. (Tese), 1969. 105p.

1. Hitchcock. A.A. The Grasses of Central America. Contr. U.S. Nat. Herbarium, 24 (9): 557 762, 1930.

I. Pedreira, J.V.S. Crescimento estacional dos eapins coloniảo (Panicum maximum Jacq.), gordura (Melinis minutiflora Pol de Beauv.), jaraguá (Hyparrhenia rufa (Ness) Stapf.) e pangola de Taiwan A-24 (Digitaria pentzii Stent.). Piracicaba, ESALQ-USP. (Tese), 1972. 117p.

0. Potztal, E. Graminales, in Syllabus der Pflanzenfamilien, Zwölfte Auflage, II Band, Berlin-Nikolassee, Gebrūder Borntraeger, 1964. $666 \mathrm{p}$. 